\title{
Tailoring the Adsorption of Benzene on PdFe Surfaces: A Density Functional Theory Study
}

\author{
Alyssa J. R. Hensley, ${ }^{\dagger}$ Renqin Zhang, ${ }^{\dagger}$ Yong Wang, ${ }^{\dagger, \dagger}$ and Jean-Sabin McEwen ${ }^{*},, \S$ \\ ${ }^{\dagger}$ The Gene \& Linda Voiland School of Chemical Engineering and Bioengineering, Washington State University, Pullman, Washington \\ 99164, United States \\ ${ }^{*}$ Institute for Integrated Catalysis, Pacific Northwest National Laboratory, Richland, Washington 99352, United States \\ ${ }^{\S}$ Department of Physics and Astronomy, Washington State University, Pullman, Washington 99164, United States
}

\section{Supporting Information}

ABSTRACT: Bimetallic surfaces have been found to greatly improve the performance of numerous chemical processes due to synergistic interactions between the metal components. To be able to tailor the adsorption of aromatic molecules of these surfaces, the synergistic interactions within the surface and their effects on adsorbates must be elucidated. In this work, we examine the energetic and electronic interaction between benzene and several model PdFe bimetallic surfaces, with low and high Pd coverage limits, using density functional theory and compare our results with the adsorption of benzene on a pure $\mathrm{Fe}$ (110) surface. The adsorption energy trends on these model surfaces show that the interactions between the Pd and Fe significantly decrease the strength of benzene's adsorption on surface Pd without significantly weakening its adsorption on the adjacent surface Fe. From the electronic analyses, the decreased adsorption strength of benzene on the model PdFe surfaces is due to the shift in the Pd's dband center away from the Fermi level. These results show that aromatic compounds will preferentially adsorb onto any exposed $\mathrm{Fe}$ in a PdFe surface due to the greater availability of electronic states near the Fermi level. Therefore, under typical catalytic conditions, the strength of the adsorption of benzene can be tailored on the basis of the amount of Pd added to an Fe surface because increasing the concentration of $\mathrm{Pd}$ in the surface will increase the amount of interaction between the adsorbate and the modified surface Pd.

\section{INTRODUCTION}

The application of bimetallic surfaces has been found to greatly improve the performance of numerous chemical processes. ${ }^{1}$ Interest in the synergistic interactions within bimetallic systems has grown rapidly since its humble beginning in petroleum refining. Researchers discovered that combining platinum and iridium, rhenium, or tin provided a superior catalytic performance over the pure platinum catalyst. ${ }^{2-8}$ Combining the platinum and rhodium metals was found to improve the oxidation of hydrocarbons, carbon monoxide, and nitrogen oxides, and this combination of metals is currently used in catalytic converters in automotives. ${ }^{9-11}$ The application of an iron-cobalt alloy to the traditional formation of hydrocarbons from syngas using the Fischer-Tropsch reaction was studied and resulted in a catalyst that exhibited a strong resistance to carburization and a higher selectivity to the water gas shift reaction. $^{12-16}$ Further studies have shown that bimetallic systems can be applied to improve the oxidation of methanol by combining platinum and ruthenium which has applications in direct methanol fuel cells. ${ }^{17-20}$

Recently, a novel PdFe catalyst was developed for the HDO of phenolic compounds. ${ }^{21}$ The reaction activity for a model compound of guaiacol was studied, and it was shown that this catalyst had a higher guaiacol conversion and benzene selectivity than either of the pure Pd or pure Fe catalysts. Results from scanning transmission electron microscopy along with electron dispersion microscopy, temperature programmed reduction, extended $\mathrm{X}$-ray adsorption fine structure, and density functional theory (DFT) demonstrated that the surface Pd was modified by the PdFe interaction. These surface interactions between the metal components clearly work together in a synergistic manner to improve the catalytic activity. The further elucidation of the interactions between the metal components upon the adsorption of a model compound is needed so as to better understand the nature of catalytic sites and optimize the bimetallic system.

The structure of a bimetallic surface is often nonhomogeneous due to the metals' relative surface segregation tendency and surface energy, and these nonhomogeneous structures can have a large effect on the behavior of that surface. ${ }^{22-26}$ The above experimental work on the PdFe catalyst showed two dominant structures of a Pd host with Fe layers and an Fe host with Pd layers. These different structures can have vastly different effects on the surface-adsorbate interactions and are important for providing a deeper understanding of the interactions within the surfaces.

In this work, we present a study on the adsorption of benzene on the Fe (110) facet and several model PdFe surfaces

Received: June 28, 2013

Revised: October 7, 2013

Published: October 15, 2013 
composed of host Pd (111) and Fe (110) surfaces. These facets were chosen as they are the closest packed facets of the face centered cubic (fcc) and body centered cubic (bcc) unit cells. ${ }^{27}$ Benzene was chosen as a model molecule because it contains the minimum number of atoms possible in an aromatic compound, and it has a high level of symmetry. ${ }^{28}$ The adsorption preference of this model molecule on the PdFe surface will show us which metal acts as the active catalytic phase of the novel PdFe catalyst.

The surface adsorption of benzene has been thoroughly studied on the Pd $(111)^{29-33}$ and the Fe $(100)^{34,35}$ surfaces using DFT. A comparison of these pure surfaces without van der Waals corrections shows that benzene adsorbs more strongly onto the Pd (111) facet while the molecule's distortion is more pronounced on the $\mathrm{Fe}$ (100) surface. However, the differences in these measures of the strength of the adsorption of benzene are not significant and therefore do not provide substantial evidence upon which to speculate about the surface interactions within a PdFe bimetallic surface. To elucidate these surface interactions, we will characterize the adsorption strength of the model compound on each surface and then compare the resulting changes in the density of states upon adsorption of the model compound at the most favorable site. The first surface examined will be the pure $\mathrm{Fe}$ (110) surface followed by a PdFe surface within a host Pd (111) surface, a PdFe surface within a host $\mathrm{Fe}$ (110) surface, and a $\mathrm{Fe}(110)$ surface with a single Pd atom impurity. These model PdFe surface will provide the upper and lower energy bounds for benzene's adsorption on surfaces with varying Pd concentration and, together with detailed electronic analyses of the surfaceadsorbate interactions, will allow us to quantify the effect that the bimetallic surface has on this system. In section 2, the methods employed to model these systems are described in detail. The results and discussion for the adsorption of benzene on all model surfaces are presented in section 3. Finally, conclusions will be drawn in section 4 .

\section{COMPUTATIONAL DETAILS}

The DFT calculations presented here were all performed using the Vienna ab initio simulation package (VASP) code. ${ }^{36,37}$ The implementation of VASP's projector augmented waves $(\mathrm{PAW})^{38,39}$ for the electron-ion interactions along with the generalized gradient approximation (GGA) for exchangecorrelation effect are widely used methods for the adsorption of aromatic molecules onto metal surfaces. ${ }^{40}$ However, a recent study showed that the inclusion of van der Waals corrections can have a large effect upon the adsorption strength of even the chemisorption of benzene on noble metal surfaces. ${ }^{28,29}$ To determine if these corrections would have a similarly large impact on the adsorption of benzene on the Fe (110) surface, adsorption results from VASP's newly developed optB $88^{41}$ exchange-correlation functional was compared with those obtained using the Perdew, Burke, and Ernzerhof (PBE) ${ }^{42,43}$ functional.

To minimize the interaction between benzene adsorbates due to VASP's periodic boundary conditions, the systems with surfaces that did not buckle upon benzene adsorption and remained flat were studied using $p(4 \times 4)$ supercells. Surfaces that underwent buckling due to the adsorption of benzene were modeled using $\mathrm{p}(5 \times 5)$ supercells, and all systems were modeled with the substrates composed of four atomic layers. These supercell sizes were chosen to model the low coverage limit of benzene on each surface since increasing the supercell size from $\mathrm{p}(4 \times 4)$ to $\mathrm{p}(5 \times 5)$ only varied the adsorption energy by 0.03 and $0.06 \mathrm{eV}$ for the $\mathrm{Pd} / \mathrm{Fe} / \mathrm{Pd}(111)$ and buckled $\mathrm{Pd} / \mathrm{Fe}$ (110) surfaces, respectively. Additional details on the supercell size tests for the buckled Pd/Fe (110) surface are presented in the Supporting Information. The bottom two layers were kept fixed in their bulk positions, and all other atoms were allowed to relax, including the adsorbate.

Due to the periodic boundary conditions employed in VASP, all calculations were performed with $\sim 10 \AA$ vacuum present between the benzene adsorbate and the repeated supercell. A $(3 \times 3 \times 1)$ k-points Monkhorst-Pack ${ }^{44}$ mesh was employed to sample the unit cells, and the plane waves were expanded to a kinetic energy of $400 \mathrm{eV}$. This $\mathbf{k}$-points mesh was extended to a $(7 \times 7 \times 1)$ and $(5 \times 5 \times 1)$ grid for the calculation of the density of states with the $\mathrm{p}(4 \times 4)$ and $\mathrm{p}(5 \times 5)$ supercells, respectively. The Methfessel-Paxton ${ }^{45}(N=1)$ smearing method was used with a smearing width of $0.1 \mathrm{eV}$ to improve convergence, and the total energy was extrapolated to $0 \mathrm{~K}$. It is well-known that the amount of spin polarization in $\mathrm{Pd}$ can be highly sensitive to the smearing width. ${ }^{46,47}$ Therefore, the adsorption of benzene on one of the model PdFe surfaces was tested with a smearing width of $0.2 \mathrm{eV}$, and it was found that the adsorption energy varied by $0.04 \mathrm{eV}$ and the Pd's magnetic moment $0.02 \mu_{\mathrm{B}}$, confirming that the sensitivity of Pd toward spin polarization is not a concern in this case. Due to the ferromagnetic nature of $\mathrm{Fe}$, spin polarization was found to be significant and was accounted for in all calculations. In addition to the spin polarization, the effect of dipole interactions between the consecutive supercells was considered to be significant and dipole corrections were imposed in each calculation performed. ${ }^{48}$ The total energy was converged to $10^{-4} \mathrm{eV}$ for all systems, and the systems were considered to be optimized when the forces between atoms were less than 0.03 $\mathrm{eV} / \AA$.

Three Fe surfaces and one Pd surface were examined as the PdFe metal substrate; a pure Fe (110) surface, a host Pd (111) with the first subsurface layer replaced with pure $\mathrm{Fe}$, a host $\mathrm{Fe}$ (110) with the surface layer replaced with Pd, and an Fe (110) surface with a single Pd surface impurity. The Fe (110) and Pd (111) facets were chosen because they are the closest packed facet in the bcc Fe and fcc Pd. ${ }^{27}$ The Fe and Pd layered surfaces examined here within the $\mathrm{Pd}(111)$ and $\mathrm{Fe}$ (110) host were determined to be the most favorable configuration of these systems by Sun et al. ${ }^{21}$ These results are supported by the results of Ruban et al., ${ }^{49,50}$ who showed that a Pd impurity in host $\mathrm{Fe}(110)$ has the strong tendency to surface segregate while an Fe impurity within a host Pd (111) was shown to have a strong antisegregation tendency. This behavior is further supported by the surface energy of the two metals. Pd has a lower surface energy than $\mathrm{Fe}$ and will therefore preferentially segregate to the surface. ${ }^{51}$ The lattice constants of both Pd and Fe were determined theoretically by minimizing the total energy of a Pd fcc and Fe bcc unit cell. This resulted in a Pd and Fe lattice constant of 3.957 and $2.827 \AA$, respectively. These results agree well within the range of other theoretical results and the experimental values and remained constant with the addition of van der Waals corrections. ${ }^{52-54}$

In addition to the surfaces above, the segregation behavior within the two energetically stable Pd and Fe alloys, ${ }^{55} \mathrm{PdFe}$ and $\mathrm{Pd}_{3} \mathrm{Fe}$, was investigated. The trend of the segregation of $\mathrm{Pd}$ to the surface established in our previous work $^{21}$ was also observed for these bulk alloy surfaces. It was therefore assumed that the trends found here for benzene's adsorption on these 
surfaces would be nearly identical to its adsorption on the Pd (111) host surface with Fe impurity and was not studied in this work. The details of these segregation calculations are presented in the Supporting Information.

The surfaces and adsorption sites were evaluated using the adsorption energy. This was calculated as the difference in the energy of the molecule adsorbed on the surface and the energy of the individual surface and adsorbate molecule according to

$$
E_{\text {ads }}=E_{\text {surface+molecule }}-E_{\text {molecule }}-E_{\text {surface }}
$$

Another method of comparing the effect of the various adsorption sites and surfaces on the benzene adsorbate is the distortion energy. This is the energy the adsorbate molecule gains due to its geometric distortion from the interaction with the metal surface. ${ }^{56}$ This energetic information will be calculated according to

$$
E_{\text {dist }}=E_{\text {molecule }}^{\text {distorted geometry }}-E_{\text {molecule }}^{\text {free gas geometry }}
$$

This energy difference allows for a second evaluation of the strength of the interaction between the adsorbate and the surface. For a chemisorbed system, the adsorbed molecule will be distorted from its free gas geometry due to its electronic interaction with the surface. The surface-adsorbate interaction will increase as the distortion energy increases. However, this does not necessarily result in a most favorable adsorption site because the distortion can outweigh the interaction between surface and adsorbate. ${ }^{35}$

\section{RESULTS AND DISCUSSION}

3.1. Benzene Adsorption on the Fe (110) Surface. On the $\mathrm{Fe}$ (110) surface, benzene can adsorb in the top, short bridge, long bridge, and 3-fold sites with a ring orientation of either 0 or $30^{\circ}$ with respect to the vertical $\mathrm{Fe}$ rows. When the ring has an orientation of 0 or $30^{\circ}$, two of the $\mathrm{C}-\mathrm{C}$ bonds within the benzene adsorbate are perpendicular or parallel to the vertical Fe rows. These possible adsorption sites are shown in Figure 1.

To determine the effect of van der Waals forces on this adsorption system, all sites were examined using both the PBE and optB88 functionals. In both cases, the long bridge $30^{\circ}$, long bridge $0^{\circ}$, short bridge $0^{\circ}, 3$-fold $30^{\circ}$, and 3 -fold $0^{\circ}$ sites were all found to have stable adsorption configurations while the short bridge $30^{\circ}$, top $0^{\circ}$, and top $30^{\circ}$ positions were unstable and shifted to a more favorable site. The adsorption energy and geometric distortion results are shown in Table 1.

The five stable adsorption sites have similar adsorption and distortion energies with the 3 -fold $30^{\circ}$ being the most favorable location for benzene adsorption. All stable sites show a similar increase in both the $\mathrm{C}-\mathrm{C}$ bond length and $\mathrm{C}-\mathrm{H}$ dihedral angle of the benzene ring due to surface interactions. The ring stretches during adsorption as the carbon atoms within the ring form partial bonds with the Fe (110) surface. The inclusion of the van der Waals corrections with the optB88 functional in this system increases the adsorption energy of all sites by $\sim 0.72 \mathrm{eV}$ while the structural deformations remain largely unchanged. Overall, there is a slight decrease in the distortion energy of each site with the addition of van der Waals corrections. The addition of these corrections also increased the energy difference between the long bridge $0^{\circ}$ and long bridge $30^{\circ}$ sites which were nearly identical in strength with only the PBE functional. From the van der Waals corrected results, it is clear that the 3 -fold $30^{\circ}$ site is the most energetically favorable

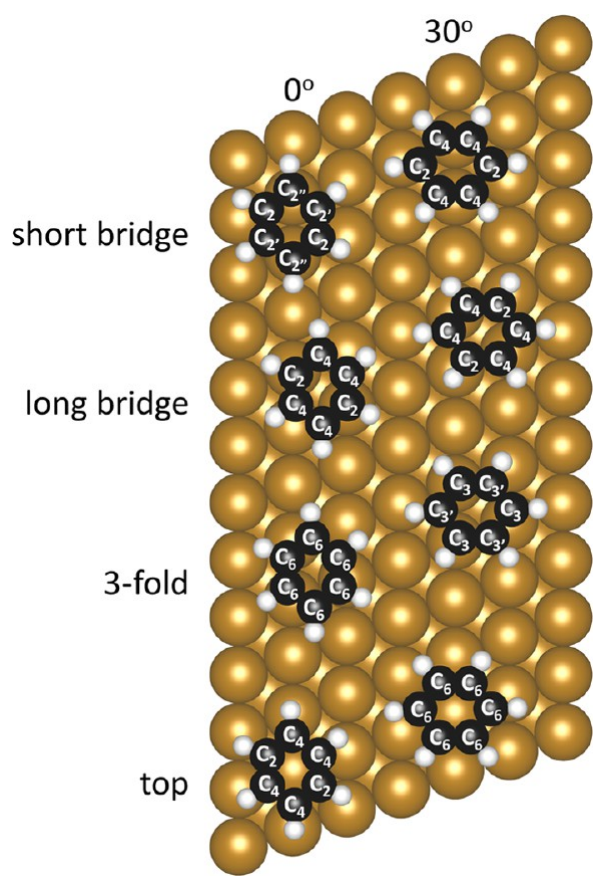

Figure 1. All possible adsorption sites for benzene on Fe (110). The white spheres represent hydrogen, the black spheres represent carbon, and the gold spheres represent iron. Each carbon atom in the aromatic ring can be classified based on its configuration relative to the $\mathrm{Fe}$ (110) surface. These configurations have been labeled according to the number of identical configurations found in a given benzene adsorption site (e.g., $\mathrm{C}_{4}$ refers to a configuration with four identical carbon atoms). The addition of the prime and double prime is used to separate different configurations that contain the same number of carbons.

adsorption site for benzene on the $\mathrm{Fe}$ (110) surface. The overall adsorption energy increase with the inclusion of van der Waals corrections is in agreement with Liu et al. ${ }^{32,33}$ who observed similar, significant increases in adsorption energy when benzene adsorbed onto both noble and transition metal surfaces. Because van der Waals corrections have a significant effect upon the adsorption of benzene on Fe (110), all the following calculations were performed using the optB88 functional.

The electronic nature of the interaction between the benzene adsorbate and the $\mathrm{Fe}$ (110) surface was investigated through the differential charge density. The differential charge density shows the movement of electrons in the system as the benzene molecule adsorbs onto the $\mathrm{Fe}(110)$ surface and was calculated according to

$$
\Delta \rho=\rho_{\text {molecule }+ \text { surface }}-\rho_{\text {molecule }}-\rho_{\text {surface }}
$$

The 3-fold $30^{\circ}$ site was chosen for further examination because it was found to have the strongest adsorption on the Fe (110) surface. This shift of electrons during adsorption for this site is shown in Figure 2. When benzene adsorbs on the surface, the surface and adsorbate exchange electrons, creating the partial covalent bonds characteristic of chemisorption. The creation of these bonds comes at the cost of a loss of electrons around the Fe surface and the bottom of the aromatic ring.

These electronic exchanges can be further elucidated by an examination of the local density of states (LDOS) for both an adsorbed ring carbon and a carbon-bonded $\mathrm{Fe}$ atom. These comparisons were made using the most favorable adsorption 
Table 1. Energetic and Geometric Results for Benzene Adsorbed on Fe (110) in All Possible Sites ${ }^{a}$

\begin{tabular}{|c|c|c|c|c|c|}
\hline site & $E_{\text {ads }}(\mathrm{eV})$ & $E_{\text {dist }}(\mathrm{eV})$ & $d_{\mathrm{C}-\mathrm{C}}(\AA)$ & $\theta_{\mathrm{C}-\mathrm{H}}(\mathrm{deg})$ & $d_{\mathrm{C}-\mathrm{M}}(\AA)$ \\
\hline free benzene & & & 1.40 & 0 & \\
\hline short bridge $0^{\circ}$ & $-1.11(-1.82)$ & $1.20(1.14)$ & $1.45(1.45)$ & $19,25(18,24)$ & $1.98(2.00)$ \\
\hline short bridge $30^{\circ}$ & \multicolumn{5}{|c|}{ unstable, shift to 3 -fold $30^{\circ}$} \\
\hline long bridge $0^{\circ}$ & $-1.17(-1.88)$ & $1.13(1.07)$ & $1.44(1.44)$ & $20,25(19,25)$ & $2.05(2.07)$ \\
\hline long bridge $30^{\circ}$ & $-1.16(-1.91)$ & $1.19(1.12)$ & $1.45(1.44)$ & $19,27(19,26)$ & $2.03(2.03)$ \\
\hline 3 -fold $0^{\circ}$ & $-1.20(-1.95)$ & $1.19(1.12)$ & $1.45(1.45)$ & $21,25(20,23)$ & $2.04(2.06)$ \\
\hline 3 -fold $30^{\circ}$ & $-1.21(-1.97)$ & $1.16(1.08)$ & $1.44(1.44)$ & $18,21(18,22)$ & $2.04(2.05)$ \\
\hline top $0^{\circ}$ & \multirow{2}{*}{\multicolumn{5}{|c|}{$\begin{array}{c}\text { unstable, shift to } 3 \text {-fold } 0^{\circ} \\
\text { unstable, shift to long bridge } 30^{\circ}\end{array}$}} \\
\hline & & & & & \\
\hline \multicolumn{6}{|l|}{ ontion } \\
\hline
\end{tabular}

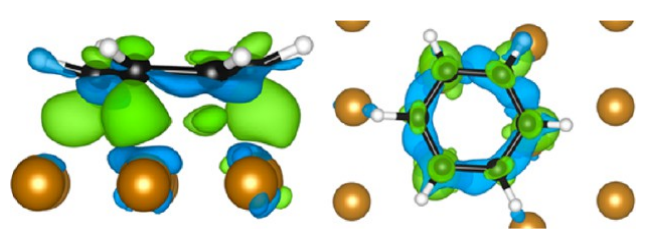

Figure 2. Differential charge density of the adsorption of benzene in the 3 -fold $30^{\circ}$ site on $\mathrm{Fe}(110)$. The isosurface level was set at 0.005 electrons $/ \AA^{3}$, and the green or blue areas represent a gain or loss of electrons. These calculations were performed with the optB88 functional.

site of 3 -fold $30^{\circ}$. In this adsorption site, there are two configurations of the aromatic ring carbons with respect to the bonding $\mathrm{Fe}$ atoms, as shown in Figure 1. The LDOS for both configurations $\left(\mathrm{C}_{3}\right.$ and $\left.\mathrm{C}_{3^{\prime}}\right)$ were examined, showing almost no difference between the LDOS of the bonded carbon atom. The LDOS of the bonded $\mathrm{Fe}$ atom shows an increased distortion in the case where one carbon atom was bonded directly to a single $\mathrm{Fe}$ atom $\left(\mathrm{C}_{3}\right)$. Figure 3 shows the LDOS for this adsorbed carbon atom and its associated carbon-bonded $\mathrm{Fe}$ atom both before and after adsorption.

Here, we show both the spin up and spin down states for the bonded $\mathrm{Fe}$ atom along with the spin up states for the ring

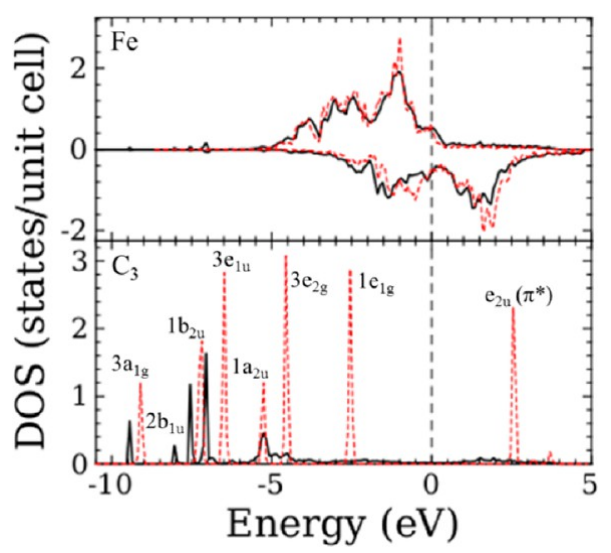

Figure 3. LDOS for the adsorption of benzene on Fe (110) in the 3fold $30^{\circ}$ position for both the spin up and spin down states of a carbon-bonded $\mathrm{Fe}$ atom before (dotted line) and after (solid line) adsorption and the spin up states for a benzene ring carbon both before (dotted line) and after (solid line) adsorption. These calculations were performed using the optB88 functional, and $E_{\mathrm{F}}$ has been set to zero. carbon. The spin down states for the ring carbon were also examined, and the difference in the LDOS between the two cases was found to be negligible. Previous calculations have shown that the peaks above the Fermi energy in the LDOS for the benzene molecule before adsorption correspond to the antibonding $\pi^{*}$ orbitals while those below that value represent the bonding $\sigma$ and $\pi$ orbitals of the benzene molecule. ${ }^{57}$ As benzene adsorbs onto the $\mathrm{Fe}(110)$ surface, the energy of the adsorbate's molecular orbitals shift to higher binding energies, as shown in Table 2. Also shown in Table 2 are the shifts in benzene's molecular orbitals due to adsorption on the other surfaces examined in this work.

These shifts to higher orbital binding energies are similar to those seen on $\mathrm{Ni}(111),{ }^{57}$ where the highest three orbitals shift by approximately $1.2,0.7$, and $1.9 \mathrm{eV}$, respectively, on the $\mathrm{Fe}$ (110) surface. Such shifts could also, in principle, be compared to the measured ones as obtained with ultraviolet photoelectron spectroscopy (UPS) techniques, as done in the case of the $\mathrm{Ni}$ (111) surface, ${ }^{57}$ although such experiments have not yet been performed on Fe single crystal surfaces. The highest occupied orbital peaks also broaden due to their overlap with the $3 \mathrm{~d}$ orbital of the Fe atom. These shifts in the binding energies of the benzene's orbitals show that the highest occupied orbitals are most affected by the adsorption. This is due to the larger degree of overlap between the $1 \mathrm{e}_{1 \mathrm{~g}}$ and $3 \mathrm{e}_{2 \mathrm{~g}}$ orbitals and the electronic states of the $\mathrm{Fe}$ surface, which can be seen more clearly in the $\mathrm{p}_{x}, \mathrm{p}_{y}$, and $\mathrm{p}_{z}$ decomposition shown in Figure S7 of the Supporting Information. The overlap between the adsorbate's highest occupied orbitals and the Fe surface was further studied by calculating the partial charge density for each orbital labeled in Figure 3 and are shown in Figure S8 of the Supporting Information. From these charge densities, it is clear that the majority of electron exchange between surface and adsorbate occurs with the adsorbate's HOMO and LUMO levels.

In addition to the changes observed in the benzene LDOS, the electronic structure of the bonded $\mathrm{Fe}$ atom, as seen in its LDOS, is also affected by the adsorption of benzene. The spin up states have shifted toward the Fermi level, and several smaller peaks have appeared in these states in the energy range of -8.0 to $-6.0 \mathrm{eV}$. The appearance of these peaks is due to the overlap with the $3 \mathrm{e}_{1 \mathrm{u}}$ and $1 \mathrm{a}_{2 \mathrm{u}}$ orbitals of the adsorbate. These changes in the electronic structure of the bonded $\mathrm{Fe}$ atom cause the magnetic moment of this atom to decrease to $1.786 \mu_{\mathrm{B}}$ from $2.477 \mu_{\mathrm{B}}$. This effect is similar to that seen on the $\mathrm{Fe}(100)$ surface. $^{35}$ 
Table 2. Orbital Binding Energies (eV) for Benzene Both in the Free Gas Form and in the Adsorbed Form onto the Most Favorable Sites on the Surfaces Fe (110), Pd/Fe/Pd (111), Pd/Fe (110), and Fe (110) with a Pd Impurity ${ }^{a}$

\begin{tabular}{rlcccc}
\hline orbital & free & $\mathrm{Fe}(110)$ & $\mathrm{Pd} / \mathrm{Fe} / \mathrm{Pd}(111)$ & $\mathrm{Pd} / \mathrm{Fe}(110)$ & $\mathrm{Fe}(110)$ with $\mathrm{Pd}\left(1^{\text {st }} / 2^{\text {nd }}\right.$ sites $)$ \\
\hline $1 \mathrm{e}_{\mathrm{lg}}(\pi)$ & -2.55 & -4.49 & -3.24 & -3.91 & $-4.30 /-4.19$ \\
$3 \mathrm{e}_{2 \mathrm{~g}}(\sigma)$ & -4.56 & -5.24 & -4.71 & -4.71 & $-5.37 /-5.26$ \\
$1 \mathrm{a}_{2 \mathrm{u}}(\pi)$ & -5.25 & -6.40 & -5.45 & -5.14 & $-6.28 /-6.24$ \\
$3 \mathrm{e}_{\mathrm{lu}}(\sigma)$ & -6.49 & -7.06 & -5.94 & -6.01 & $-7.26 /-7.06$ \\
$1 \mathrm{~b}_{2 \mathrm{u}}(\sigma)$ & -7.18 & -7.55 & -6.68 & -6.73 & $-7.68 /-7.56$ \\
$2 \mathrm{~b}_{1 \mathrm{u}}(\sigma)$ & -7.26 & -8.05 & -7.42 & -9.05 & $-8.00 /-7.97$ \\
$3 \mathrm{a}_{1 \mathrm{~g}}(\sigma)$ & -9.11 & -9.45 & -9.22 & & $-9.48 /-9.37$ \\
${ }^{a}$ Calculations &
\end{tabular}

Overall, these results show that there is a strong electronic interaction between the benzene adsorbate and the Fe surfaces. The donation and backdonation of electrons to and from the surface and adsorbate create the partial covalent bonds characteristic of chemisorption and verify the strong adsorption energy observed for this system.

3.2. Benzene Adsorption on a Pd/Fe/Pd (111) Surface. The first PdFe surface examined was a host Pd (111) system where the first subsurface layer is composed entirely of Fe. In our previous work, ${ }^{21}$ this surface was found to be the most favorable near-surface structure by comparing various configurations of pure $\mathrm{Fe}$ and mixed PdFe layers within the first three layers of the Pd host. On the (111) facet, benzene can adsorb onto the bridge, hcp, fcc, and top sites with the ring oriented at either 0 or $30^{\circ}$ with respect to the horizontal rows of Pd. These adsorption sites are shown in Figure 4.

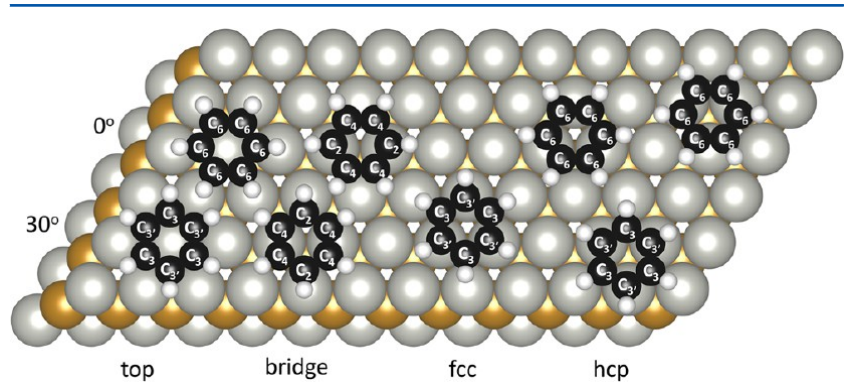

Figure 4. All possible adsorption sites for benzene on a model $\mathrm{Pd} / \mathrm{Fe} /$ Pd (111) surface. The host material is the Pd (111) facet. The Fe placed as a pure layer in the first subsurface layer of the system is the most favorable configuration for this system. The white spheres represent hydrogen, the black spheres represent carbon, the silver spheres represent palladium, and the gold spheres represent iron. The labeling of ring carbons is as in Figure 1.

The strength of the adsorption and the relative geometric distortions in the adsorbate were calculated, and these results are presented in Table 3.

The majority of the adsorption sites examined were found to be stable with only the top $30^{\circ}$ shifting into the more favorable fcc $30^{\circ}$ site. Overall, the most favorable adsorption site was the $\mathrm{fcc} 30^{\circ}$ site with an adsorption energy of $-1.10 \mathrm{eV}$, but the largest difference in adsorption energies is $0.09 \mathrm{eV}$, making all of the stable sites nearly identical. To illustrate the significant effect that van der Waals corrections have on the adsorption of aromatic compounds on transition metal surfaces, the adsorption energy of this most favorable site was calculated without these corrections. The resulting adsorption energy was found to be $-0.23 \mathrm{eV}$ with negligible changes in the distortion of the molecule itself. The addition of the van der Waals
Table 3. Energetic and Geometric Results for Benzene Adsorbed on $\mathrm{Pd} / \mathrm{Fe} / \mathrm{Pd}$ (111) in All Possible Sites ${ }^{a}$

$\begin{array}{llllll}\begin{array}{l}\text { adsorption } \\ \text { site }\end{array} & E_{\text {ads }}(\mathrm{eV}) & E_{\text {dist }}(\mathrm{eV}) & d_{\mathrm{C}-\mathrm{C}}(\AA) & \theta_{\mathrm{C}-\mathrm{H}}(\mathrm{deg}) & d_{\mathrm{C}-\mathrm{M}}(\AA) \\ \text { free benzene } & & & 1.40 & 0 & \\ \text { bridge } 0^{\circ} & -1.02 & 0.03 & 1.41 & 3,4 & 2.75 \\ \text { bridge } 30^{\circ} & -1.07 & 0.04 & 1.40,1.41 & 3 & 2.65 \\ \text { hcp } 0^{\circ} & -1.04 & 0.04 & 1.40,1.41 & 2,3 & 2.71 \\ \text { hcp } 30^{\circ} & -1.01 & 0.04 & 1.40,1.41 & 2,4 & 2.67 \\ \text { fcc } 0^{\circ} & -1.07 & 0.04 & 1.40,1.41 & 3,4 & 2.68 \\ \text { fcc } 30^{\circ} & -1.10 & 0.04 & 1.40,1.41 & 2,4 & 2.67 \\ \text { top } 0^{\circ} & -0.91 & 0.01 & 1.40 & 0 & 3.01 \\ \text { top } 30^{\circ} & & & \text { shift to fcc } 30^{\circ} & & \end{array}$

${ }^{a}$ Adsorption energy, $E_{\text {ads }} ;$ distortion energy of the molecule, $E_{\text {dist }} ; \mathrm{C}-\mathrm{C}$ bond length, $d_{\mathrm{C}-\mathrm{C}}$; dihedral angle of hydrogen atoms, $\theta_{\mathrm{C}-\mathrm{H}}$; and the perpendicular distance from adsorbate to surface, $d_{\mathrm{C}-\mathrm{M}}$. Calculations were performed with the optB88 functional.

corrections increased the adsorption energy by $\sim 0.9 \mathrm{eV}$, which is a larger effect than that observed on the pure $\mathrm{Fe}$ (110) surface in the preceding discussion. By comparison with the optB88 results from benzene's adsorption on Fe (110) in Table 1 (values shown in parentheses), it is clear that the adsorption of benzene on this surface is much less favorable than on the pure $\mathrm{Fe}$ (110) surface. This decrease in the observed adsorption strength between benzene and the $\mathrm{Pd} / \mathrm{Fe} / \mathrm{Pd}$ (111) surface is echoed in the adsorbate's distortion energy and geometric deformations due to surface interactions. The average distortion energy for all stable sites is $\sim 0.04 \mathrm{eV}$, and the aromatic rings are barely deformed as seen in the $0.01 \AA$ increase in the $\mathrm{C}-\mathrm{C}$ bond length and the average $\mathrm{C}-\mathrm{H}$ dihedral angle increase of $3^{\circ}$. In addition to this minimal distortion in the adsorbate, the distance from the surface to the adsorbate has increased by $\sim 0.6 \AA$ as compared to the Fe (110) surface. This decreased adsorption energy and minimal molecular distortion suggests that the adsorption of benzene on this model surface is dominated by physisorption.

We have also examined the possibility that the $\mathrm{Fe}$ in this surface will surface segregate upon the adsorption of benzene due to the increase in binding strength between the adsorbate and $\mathrm{Fe}$ in the $\mathrm{Pd} / \mathrm{Fe} / \mathrm{Pd}(111)$ surface. This reversed segregation behavior was found to be energetically unfavorable, even with benzene adsorbed on the surface. These results show that even under adsorption conditions, the surface will be enriched in Pd. This work is presented in more detail in the Supporting Information.

The nature of the electronic interactions between the adsorbate and the $\mathrm{Pd} / \mathrm{Fe} / \mathrm{Pd}$ (111) surface appears to be significantly weaker that those observed on the pure Fe (110) surface. These weak electronic interactions can be visualized by 
inspecting the differential charge density for the adsorption of benzene on the fcc $30^{\circ}$ site on this surface, as shown in Figure 5.

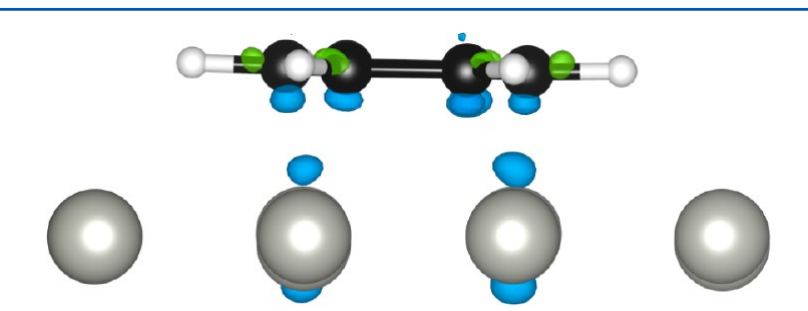

Figure 5. The differential charge density of the adsorption of benzene in the fcc $30^{\circ}$ site on $\mathrm{Pd} / \mathrm{Fe} / \mathrm{Pd}(111)$. The isosurface level and color coding are as in Figure 2. Calculations were performed using the optB88 functional.

From this side view of the adsorption site, it is clear that the adsorbate is minimally distorted by the surface interaction and sits well away from the surface. Also, the strong, partial covalent bonds formed between benzene and the pure Fe (110) surface is nonexistent between the adsorbate and the $\mathrm{Pd} / \mathrm{Fe} / \mathrm{Pd}(111)$ surface.

To further elucidate the nature of the adsorbate-surface interactions, the LDOS for the bonded carbon and surface palladium atoms were calculated and are shown in Figure 6.

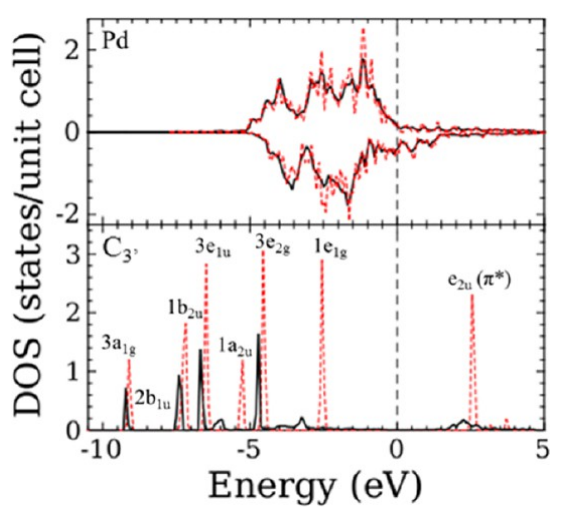

Figure 6. LDOS for the adsorption of benzene on the $\mathrm{Pd} / \mathrm{Fe} / \mathrm{Pd}$ (111) in the fcc $30^{\circ}$ position for a carbon-bonded $\mathrm{Pd}$ atom and the associated ring carbon both before (dotted line) and after (solid line) adsorption. Calculations were performed using the optB88 functional, and the $E_{\mathrm{F}}$ has been set to zero.

These comparisons were made using the most favorable adsorption site of fcc $30^{\circ}$. In this adsorption site, there are two configurations of the aromatic ring carbons with respect to the bonding $\mathrm{Pd}$ atoms $\left(\mathrm{C}_{3}\right.$ and $\left.\mathrm{C}_{3^{\prime}}\right)$, as shown in Figure 4 . The LDOS for both configurations were examined, showing almost no difference between the LDOS of the bonded carbon atom. Both carbon configurations are bonded to the same Pd atom, meaning that there is no difference in the metal's LDOS with the change in ring carbon configuration. As the $C_{3^{\prime}}$ configuration results in the bonded carbon atop the surface Pd, this situation was plotted in Figure 6. Here, we show both the spin up and spin down states for the bonded Pd atom along with the spin up states for the ring carbon. The spin down states for the ring carbon were also examined, and the difference in the LDOS between the two cases was found to be negligible.
Because the benzene adsorbs onto the $\mathrm{Pd} / \mathrm{Fe} / \mathrm{Pd}$ (111) model surface, the energy of the adsorbate's bonding orbitals shift away from the Fermi level to higher binding energies. This shift is minor compared to the Fe (110) surface results, shown in Table 2, and the interaction between the surface and adsorbate orbitals is greatly reduced. This is evident from the increase in the size of the $1 \mathrm{a}_{2 \mathrm{u}}$ and $1 \mathrm{e}_{1 \mathrm{~g}}$ bonding orbital peaks with respect to the $\mathrm{Fe}$ (110) surface, and there are still a number of states present in the area of the $e_{2 u}$ antibonding orbital above the Fermi level. Finally, the partial charge density for the benzene's HOMO and LUMO levels show almost no electronic interaction with the surface (Figure S9 of the Supporting Information). In addition to these minimal changes in the bonded ring carbon, there is almost no change in the Pd LDOS. The Pd atom's states do not shift due to the interaction, and no peaks appear in the energy range of -8.0 to $-6.0 \mathrm{eV}$ as seen in the Fe (110) LDOS.

The abrupt transition of the adsorption mechanism of benzene on the Pd surface from chemisorption to physisorption with the addition of a subsurface layer of $\mathrm{Fe}$ is similar to the electronic effects observed in the Pd within PdZn alloys. ${ }^{54,55}$ In these PdZn alloys, the LDOS of the Pd in the alloy has shifted by $\sim 2.0 \mathrm{eV}$ to below the Fermi level as compared to pure Pd. This shift brings the electronic structure of the alloy into close alignment with a noble metal structure, such as $\mathrm{Cu}$, and therefore accounts for the impeding of the adsorption of $\mathrm{CO}$ on the surface of the alloy. This shift in the Pd's LDOS was accounted for on the basis of a partial filling of the $4 \mathrm{~d}$ band due to donation of electrons from the alloyed $\mathrm{Zn}$. To compare with the PdZn alloy result, the Pd's LDOS from both a pure Pd (111) surface and the $\mathrm{Pd} / \mathrm{Fe} / \mathrm{Pd}$ (111) surface are shown in Figure 7.

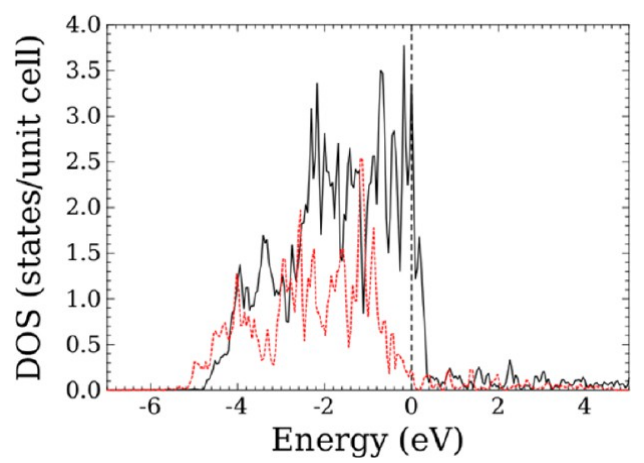

Figure 7. LDOS of Pd in a pure Pd (111) surface (black solid line) along with the spin up states of $\mathrm{Pd}$ in the $\mathrm{Pd} / \mathrm{Fe} / \mathrm{Pd}$ (111) surface (red dotted line). The calculations were performed using the optB88 functional, and $E_{\mathrm{F}}$ has been set to zero.

In the $\mathrm{Pd} / \mathrm{Fe} / \mathrm{Pd}$ (111) surface, the LDOS of the Pd has shifted to further below the Fermi level relative to the Pd (111) surface. This shift of the LDOS can be quantified by comparing the d-band center and d-bandwidth ${ }^{58,59}$ for Pd in each surface in Figure 7. These parameters, along with the number of electrons on the surface element (integrated d-states), are shown in Table 4 along with the d-band center and width for the other surfaces examined in this work.

The resulting d-band center for Pd in the Pd (111) surface is consistent with previous work. ${ }^{60}$ For the $\mathrm{Pd} / \mathrm{Fe} / \mathrm{Pd}$ (111) surface, the surface Pd's d-band center shifts by $0.5 \mathrm{eV}$ away from the Fermi level relative to the Pd (111) surface. This shift 
Table 4. d-Band Center (Spin Up/Spin Down Components), d-Band Width (Spin Up/Spin Down Components), and Number of Electrons on the Surface Elements for the Surfaces Pd (111), Fe (110), Pd/Fe/Pd (111), Pd/Fe (110), and Fe (110) with a Pd Impurity ${ }^{a}$

\begin{tabular}{lcccc}
\multicolumn{1}{c}{ surface } & element & d-band center $(\mathrm{eV})$ & d-bandwidth $\left(\mathrm{eV}^{2}\right)$ & $N_{\text {electrons }}$ \\
$\mathrm{Pd}(111)$ & $\mathrm{Pd}$ & -1.8 & 4.7 & 8.9 \\
$\mathrm{Fe}(110)$ & $\mathrm{Fe}$ & $-2.1 /-1.2$ & $5.6 / 2.2$ & 6.7 \\
$\mathrm{Pd} / \mathrm{Fe} / \mathrm{Pd}(111)$ & $\mathrm{Pd}$ & $-2.3 /-2.3$ & $7.0 / 6.7$ & 9.0 \\
$\mathrm{Pd} / \mathrm{Fe} \mathrm{(110)}$ & $\mathrm{Pd}^{1}$ & $-1.5 /-1.5$ & $3.2 / 3.3$ & 8.8 \\
$\mathrm{Pd} / \mathrm{Fe}(110)$ & $\mathrm{Pd}^{2}$ & $-2.4 /-2.4$ & $7.4 / 7.1$ & 8.7 \\
$\mathrm{Fe}(110) \mathrm{Pd}$ impurity & $\mathrm{Pd}$ & $-2.9 /-3.1$ & $10.6 / 10.6$ & 9.1 \\
$\mathrm{Fe}(110) \mathrm{Pd}$ impurity & $\mathrm{Fe}$ & $-2.1 /-1.3$ & $5.7 / 2.4$ & 6.8
\end{tabular}

${ }^{a}$ Number of electrons on the given surface element in the given surface, $N_{\text {electrons }}$. These calculations were performed with the optB88 functional.

in the d-band center accounts for the significant decrease in the absorption energy of benzene and is consistent with previous work on bimetallic, sandwich structure surfaces. ${ }^{61}$ The shift in the d-band center due to bimetallic interactions has been attributed to either a transfer of electrons between the metal components or due to a hybridization of the metal's orbitals due to the overlap between the d-orbitals. ${ }^{62}$ It is clear from Table 4 that while the number of electrons on the surface Pd does not significantly change between the $\mathrm{Pd}$ and $\mathrm{Pd} / \mathrm{Fe} / \mathrm{Pd}$ (111) surfaces, the width of Pd's d-band increases by $\sim 2.0 \mathrm{eV}^{2}$. This suggests that the shift in the d-band center that prevents adsorption is caused by the hybridization of the Pd's 4d-band with that of the subsurface Fe's 3d-band and not due to a partial filling of Pd's 4d-orbital as seen in the PdZn surfaces. Overall, these electronic interactions cause the surface to be unconducive to the adsorption of aromatic molecules.

3.3. Benzene Adsorption on a Pd/Fe (110) Surface. The second PdFe surface examined was a host Fe (110) system with the surface layer composed entirely of Pd. This surface was found to be the most favorable near-surface structure in our previous work ${ }^{21}$ which compared various configurations of pure $\mathrm{Pd}$ and mixed PdFe layers within the first three layers of the Fe host. Upon the adsorption of benzene, the previously flat, stable surface spontaneously buckled and the Pd layer formed a pseudostepped surface where a row of Pd atoms comes out of the surface as shown in Figure 8.

As the benzene is removed, the surface remains buckled and the energy difference per surface atom between these two systems is $0.35 \mathrm{eV} /$ atom, with the buckled surface being the more favorable surface. This shows that, overall, the most stable $\mathrm{Pd} / \mathrm{Fe}$ (110) surface is where the Pd buckles into a pseudostepped surface. The possibility that this surface was artificial was tested by removing the Pd adatom row (Figure S2 of the Supporting Information), but it was determined that the buckled surface with the adatom row had a lower relative surface energy and was not an artificial system (see Supporting Information). The buckling of the Pd in this surface could be due to the changes in the $\mathrm{Pd}-\mathrm{Pd}$ bond length. In a pure $\mathrm{Pd}$ system, the Pd-Pd bond length is $2.80 \AA$. This bond length on the $\mathrm{Pd} / \mathrm{Fe}(110)$ flat surface has been decreased to $2.45 \AA$ while the buckling of the surface increases the bond length to $2.77 \AA$. This increase in the Pd-Pd bond length decreases the stress in the top layer, accounting for the increased stability of the buckled surface.

The adsorption of benzene on this buckled surface was studied in the bridge $0^{\circ}$, bridge $30^{\circ}$, step, and top sites, where the 0 and $30^{\circ}$ notations represent the aromatic ring orientation with respect to the vertical rows of $\mathrm{Pd}$. These adsorption sites are shown in Figure 9.
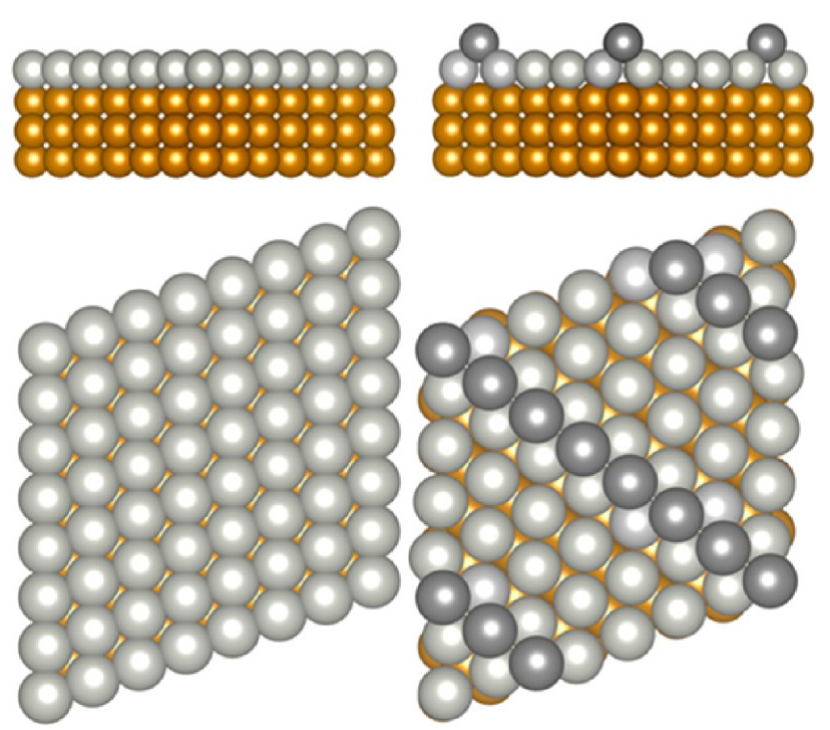

Figure 8. Comparison of the buckled and flat surface of $\mathrm{Pd} / \mathrm{Fe}$ (110). The color coding of the spheres are as in Figure 4 with the dark gray spheres representing the Pd adatom row.

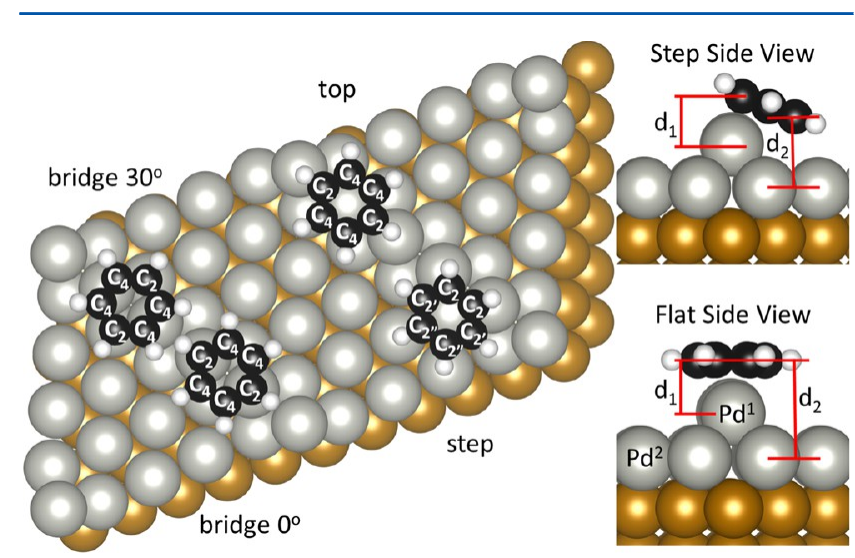

Figure 9. Favorable adsorption sites for benzene on a model $\mathrm{Pd} / \mathrm{Fe}$ (110) surface. The host material is the Fe (110) facet. The Pd placed as a pure layer on the surface of the system is the most favorable configuration for this system. The color coding of the spheres and labeling of ring carbons are as in Figure 4.

The strength of the benzene's adsorption on these various sites and the resulting relative geometric distortions in the adsorbate are presented in Table 5 .

The adsorption of benzene on this buckled surface shows a significant increase in the adsorption strength as compared to the $\mathrm{Pd} / \mathrm{Fe} / \mathrm{Pd}(111)$ surface while all sites have an adsorption 
Table 5. Energetic and Geometric Results for Benzene Adsorbed on Pd/Fe (110) in All Possible Sites ${ }^{a}$

\begin{tabular}{lccccc}
$\begin{array}{c}\text { adsorption } \\
\text { site }\end{array}$ & $E_{\text {ads }}(\mathrm{eV})$ & $E_{\text {dist }}(\mathrm{eV})$ & $d_{\mathrm{C}-\mathrm{C}}(\AA)$ & $\theta_{\mathrm{C}-\mathrm{H}}(\mathrm{deg})$ & $\begin{array}{c}d_{\mathrm{C}-\mathrm{M}} \\
\left(d_{1} / d_{2}\right)\end{array}(\AA)$ \\
$\begin{array}{c}\text { free } \\
\text { benzene }\end{array}$ & \multicolumn{5}{c}{1.40} \\
bridge $0^{\circ}$ & -1.75 & 0.20 & $1.41,1.43$ & 1,10 & $2.39 / 4.32$ \\
bridge $30^{\circ}$ & -1.77 & 0.28 & $1.42,1.43$ & 1,14 & $2.12 / 4.06$ \\
top & -1.87 & 0.29 & 1.42 & 12,13 & $2.06 / 3.13$
\end{tabular}

${ }^{a}$ Adsorption energy, $E_{\text {add }}$; distortion energy of the molecule, $E_{\text {dist }} ; \mathrm{C}-\mathrm{C}$ bond length, $d_{\mathrm{C}-\mathrm{C}}$; dihedral angle of hydrogen atoms, $\theta_{\mathrm{C}-\mathrm{H}}$; and the perpendicular distance from adsorbate to surface, $d_{\mathrm{C}-\mathrm{M}}$. Calculations were performed using the optB88 functional.

strength less than that found on the pure Fe (110) surface. The step site had the highest adsorption energy of $-1.87 \mathrm{eV}$ with a distortion energy of $0.29 \mathrm{eV}$. While the adsorption strength of benzene on this most favorable site is only $0.04 \mathrm{eV}$ less than that found for the Fe (110) surface, the molecule is only slightly deformed and shows a significant decrease of $0.83 \mathrm{eV}$ in the distortion energy of the molecule. This suggests that the adsorbate-surface interactions that occur within this system are significantly weaker than those found on the pure Fe (110) surface.

The increased strength of the electronic interactions between the adsorbate and the $\mathrm{Pd} / \mathrm{Fe}$ (110) surface as compared to the $\mathrm{Pd} / \mathrm{Fe} / \mathrm{Pd}$ (111) surface can be further understood by comparing the changes to the differential charge density and the LDOS between the two surfaces. The differential charge density for the adsorption of benzene of the step site of the Pd/ $\mathrm{Fe}$ (110) surface, as shown in Figure 10, shows an increase in the charge transfer between surface and adsorbate.

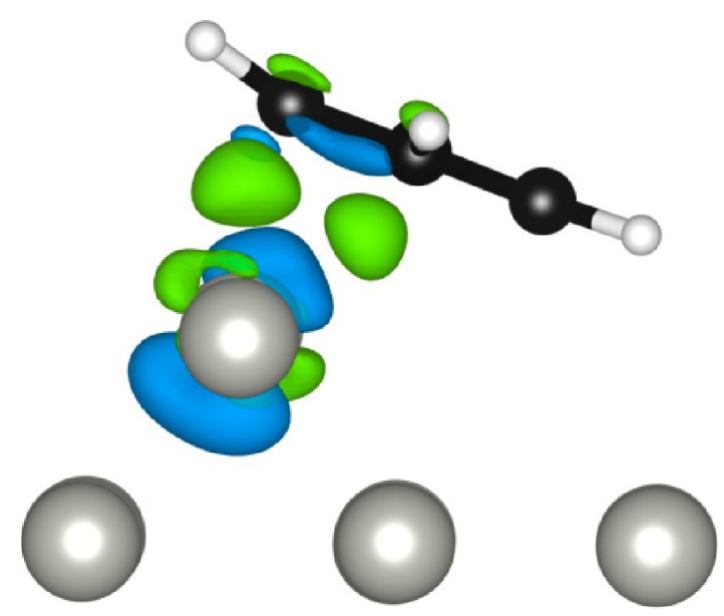

Figure 10. Differential charge density of the adsorption of benzene in the step site on $\mathrm{Pd} / \mathrm{Fe}$ (110). The isosurface level and color coding are as in Figure 2. Calculations were performed using the optB88 functional.

Because the Pd atoms in the step are further removed from the subsurface $\mathrm{Fe}$ layers, as opposed to the $\mathrm{Pd} / \mathrm{Fe} / \mathrm{Pd}$ (111) case above, these atoms begin to exchange electrons with the aromatic ring which increases the adsorption strength of this system. Here the geometric distortion is still weak because only a fraction of the ring carbons are bonding with the surface. Due to the angle of the buckled surface, the adsorbate cannot lie flat along the step without significant interaction between the benzene hydrogen and Pd surface which is highly unfavorable due to the increase in the $\mathrm{C}-\mathrm{H}$ dihedral angle upon adsorption on pure Pd surfaces. ${ }^{30,32}$

These electron transfers were further examined by calculating the LDOS for the bonded carbon and surface palladium atoms for the $\mathrm{Pd} / \mathrm{Fe}$ (110) surface. From the differential charge density (Figure 10), it is clear that there are two configurations of the aromatic ring carbons bonding with the Pd surface $\left(\mathrm{C}_{2}\right.$ and $C_{2}$, from Figure 9). The LDOS for both configurations were examined, showing almost no difference between the LDOS of the bonded carbon atom. Both carbon configurations are bonded to the same $\mathrm{Pd}$ atom, meaning that there is no difference in the metal's LDOS with the change in ring carbon configuration. As the $\mathrm{C}_{2}$ configuration results in the higher interaction between bonded carbon and the surface $\mathrm{Pd}$, this situation was plotted in Figure 11.

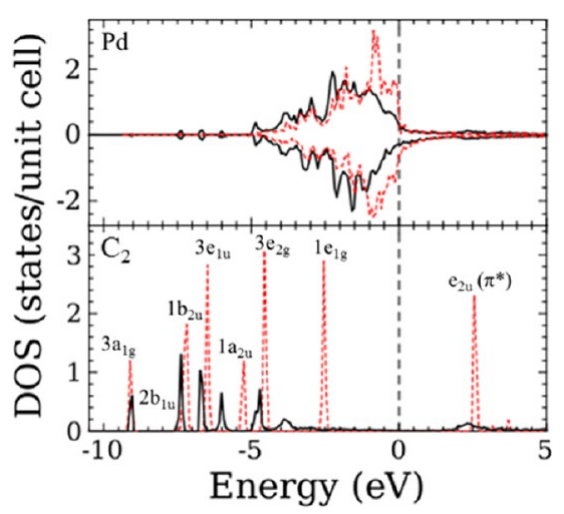

Figure 11. LDOS for the adsorption of benzene on $\mathrm{Pd} / \mathrm{Fe}(110)$ in the step position for a carbon-bonded Pd atom and the associated ring carbon both before (dotted line) and after (solid line) adsorption. The surface LDOS, both before and after adsorption, presented here is for the $\mathrm{Pd}$ in the buckled surface, and $E_{\mathrm{F}}$ has been set to zero. Calculations were performed using the optB88 functional.

Here, we show both the spin up and spin down states for the bonded Pd atom along with the spin up states for the ring carbon. The spin down states for the ring carbon were also examined, and the difference in the LDOS between the two cases was found to be negligible. Upon adsorption, the carbon's orbital peaks shift to the binding energies between those found for the $\mathrm{Fe}(110)$ and the Pd/Fe/Pd (111) surfaces (Table 2). This agrees with the adsorption energy results which place benzene's adsorption strength on the $\mathrm{Pd} / \mathrm{Fe}$ (110) surface between the $\mathrm{Pd} / \mathrm{Fe} / \mathrm{Pd}(111)$ and $\mathrm{Fe}$ (110) surfaces.

Before adsorption, both the Pd's d-band center and charge state for the adatom row ( $\mathrm{Pd}^{1}$ in Figure 9$)$ in the $\mathrm{Pd} / \mathrm{Fe}(110)$ have not significantly shifted relative to the $\mathrm{Pd}$ (111) surface while the d-bandwidth has decreased by $\sim 1.5 \mathrm{eV}^{2}$. These results suggest that the increased distance between the Pd adatom row and the subsurface $\mathrm{Fe}$ is large enough for the effect of the rehybridization of Pd's $4 \mathrm{~d}$ band to be minimal and that strong electronic interactions will occur between the benzene adsorbate and the adatom row. We find that this is indeed true as the shift in Pd's peak energies after adsorption is significantly more substantial than that seen on the $\mathrm{Pd} / \mathrm{Fe} / \mathrm{Pd}$ (111). In addition to this energy shift, the interaction with the benzene adsorbate causes several peaks to appear in the energy range for -8.0 to $-4.5 \mathrm{eV}$ while the overall number of Pd's states directly below the Fermi level have significantly 
decreased. These changes show that electrons have been both donated from the adsorbate to the surface and backdonated from the surface to the adsorbate, which is shown in more detail through the partial charge density of the HOMO and LUMO levels as seen in Figure S10 of the Supporting Information. These electronic interactions account for the increased adsorption energy for benzene on this surface relative to the $\mathrm{Pd} / \mathrm{Fe} / \mathrm{Pd}(111)$ surface and the small distortion energy for benzene on this surface relative to the $\mathrm{Fe}$ (110) surface.

The above analysis would seem to suggest that the $\mathrm{Pd} / \mathrm{Fe}$ (110) surface is as conducive to benzene adsorption as either the pure $\mathrm{Fe}$ or Pd surfaces. However, an electronic analysis of the surface Pd adjacent to the adatom row and in direct contact with subsurface $\mathrm{Fe}\left(\mathrm{Pd}^{2}\right.$ in Figure 9$)$ shows that the d-band center has shifted by $\sim 0.6 \mathrm{eV}$ below the Fermi level (Table 4). In addition to this shift, the Pd's d-bandwidth has increased by $\sim 2.6 \mathrm{eV}^{2}$ with no corresponding change in the number of electrons on said surface atom. These changes to the $\mathrm{Pd}$ electronic structure are nearly identical to those observed for the $\mathrm{Pd} / \mathrm{Fe} / \mathrm{Pd}$ (111) surface. This suggests that the adsorption of benzene on an $\mathrm{Fe}(110)$ surface coated with one layer of $\mathrm{Pd}$ will result in a physisorbed system equivalent with the $\mathrm{Pd} / \mathrm{Fe} /$ Pd (111) result and that any additional surface Pd will be far enough from the subsurface Fe to prevent Pd's hybridization and cause benzene to chemisorb onto the surface.

3.4. Benzene Adsorption on an Fe (110) Surface with a Pd Impurity. From the above results, it is clear that the complete coverage of an Fe surface with Pd results in a decrease in the interaction strength of benzene with that surface. These studies show that surfaces composed of bulk Fe will result in a higher adsorption favorability. However, PdFe surfaces that are composed of bulk Fe with a small amount of Pd can exist as opposed to the pure layered systems examined above. To address these surfaces, the effect of the addition of a single Pd into an $\mathrm{Fe}$ (110) surface on the adsorption of benzene was modeled using the 3 -fold $30^{\circ}$ site which was found above to have the most favorable adsorption of all sites on a pure $\mathrm{Fe}$ (110) surface. The distance from the adsorbate to the surface Pd atom was varied as shown in Figure 12, and the adsorption energies and structural deformations are reported in Table 6.
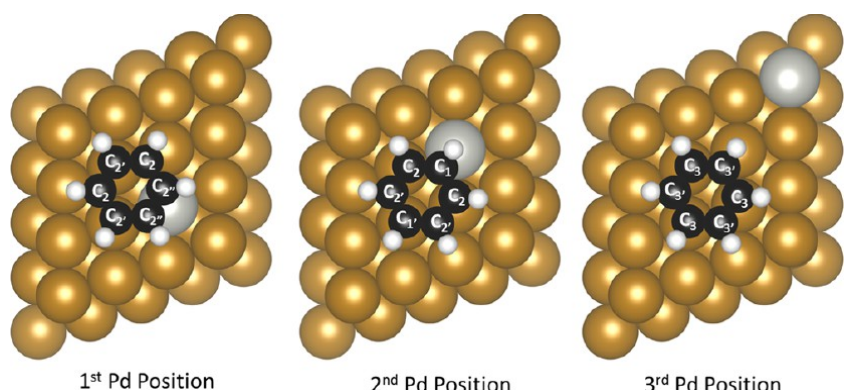

Figure 12. Adsorption of benzene on an Fe (110) surface with a Pd impurity with increasing distance from the adsorbate to the impurity atom. The color coding of the spheres and labeling of ring carbons are as in Figure 4.

These results show that the interaction between benzene and the $\mathrm{Pd}$ atom significantly decreases the adsorption energy of the system. The greatest decrease in adsorption occurs in the first case where a $\mathrm{C}-\mathrm{C}$ bond adsorbs directly over the $\mathrm{Pd}$ atom, resulting in the highest interaction between the carbon and $\mathrm{Pd}$. As the adsorbate moves away from the $\mathrm{Pd}$ impurity, the
Table 6. Energetic and Geometric Results for Benzene Adsorbed on Fe (110) with a Pd Impurity ${ }^{a}$

$\begin{array}{cccccl}\text { surface } & E_{\text {ads }}(\mathrm{eV}) & E_{\text {dist }}(\mathrm{eV}) & d_{\mathrm{C}-\mathrm{C}}(\AA) & \theta_{\mathrm{C}-\mathrm{H}}(\mathrm{deg}) & d_{\mathrm{C}-\mathrm{M}}(\AA) \\ \mathrm{Fe}(110) & -1.97 & 1.08 & 1.44,1.45 & 18,22 & 2.05 \\ 1^{\text {st }} \mathrm{Pd} & -1.55 & 0.91 & 1.42,1.45 & 14,19 & 2.10,2.33 \\ \begin{array}{c}\text { position } \\ 2^{\text {nd }} \mathrm{Pd}\end{array} & -1.80 & 0.97 & 1.44,1.45 & 17,23 & 2.09,2.15 \\ \begin{array}{c}\text { position } \\ 3^{\text {rd }} \mathrm{Pd}\end{array} & -1.90 & 1.03 & 1.43,1.45 & 20,22 & 2.02,2.09 \\ \text { position } & & & & & \end{array}$

${ }^{a}$ Adsorption energy, $E_{\text {ads }} ;$ distortion energy of the molecule, $E_{\text {dist }} ; \mathrm{C}-\mathrm{C}$ bond length, $d_{\mathrm{C}-\mathrm{C}}$; dihedral angle of hydrogen atoms, $\theta_{\mathrm{C}-\mathrm{H}}$; and the perpendicular distance from adsorbate to surface, $d_{\mathrm{C}-\mathrm{M}}$. The distance between adsorbate and $\mathrm{Pd}$ impurity increases from position 1 to position 3, and calculations were performed using the optB88 functional.

calculated adsorption energy and molecular distortion approach that found on the pure Fe (110) surface. From these results, it is clear that benzene preferentially adsorbs on the Fe surface away from the surface Pd.

The decrease in the adsorption energy of benzene on the Fe (110) surface near Pd impurity atoms can be related to observed changes in the differential charge density and LDOS for the various systems. The differential charge densities for the adsorption of benzene on the $\mathrm{Fe}$ (110) surface with a $\mathrm{Pd}$ impurity in the first and second positions are shown below in Figure 13.

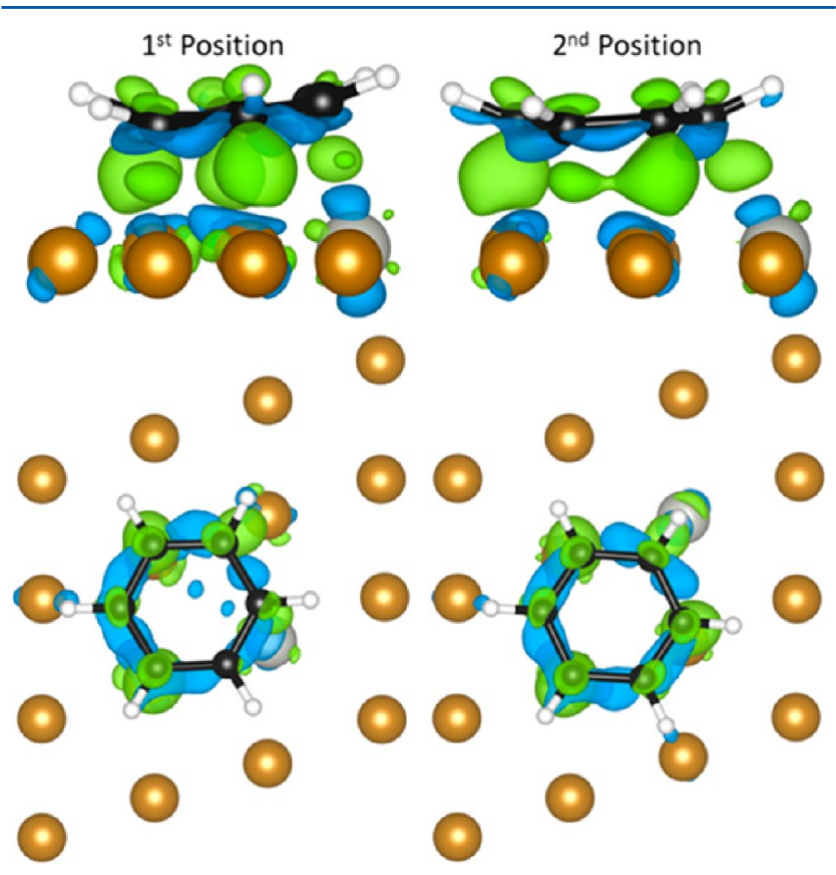

Figure 13. Differential charge density for the adsorption of benzene on an $\mathrm{Fe}$ (110) surface with a Pd impurity. The isosurface level and color coding are as in Figure 2, and calculations were performed using the optB88 functional.

A comparison of the partial bonds formed between the surface and adsorbate around the Pd atom shows that direct interaction with the surface Pd atom decreases the strength of the adsorption of benzene. As the benzene adsorbate is shifted to a lesser degree of interaction, the electron interaction between the Pd and bonded carbon atom increases. However, 

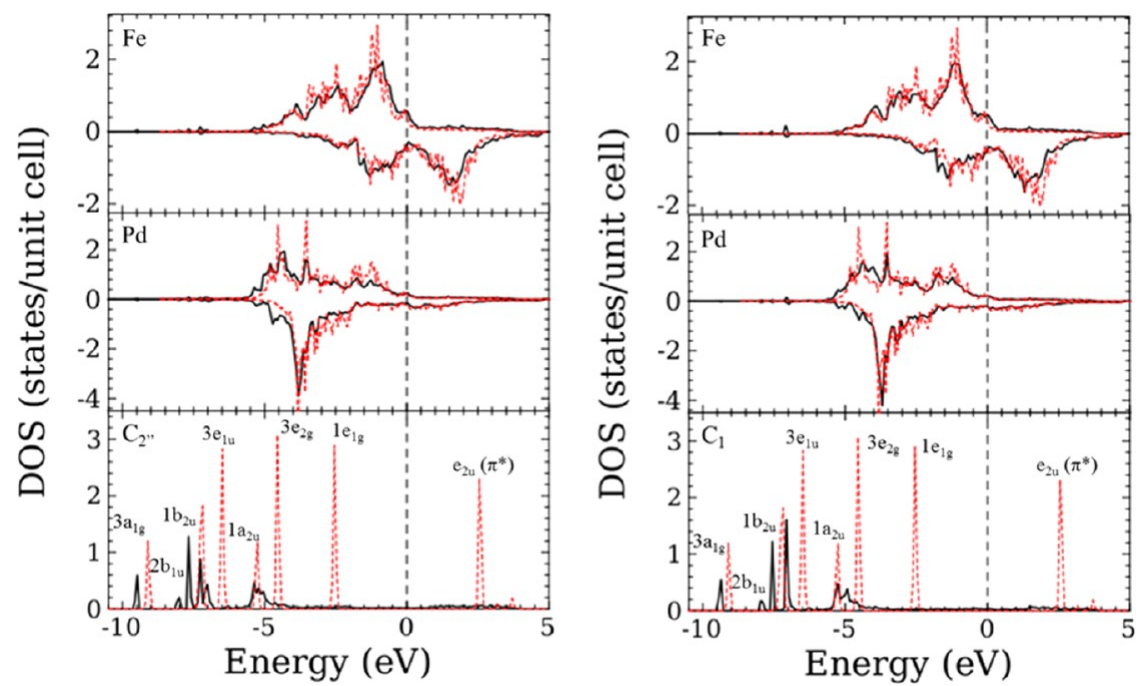

Figure 14. LDOS for a carbon-bonded Pd atom, carbon-bonded Fe atom, and the associated ring carbons both before (dotted line) and after (solid line) adsorption for the adsorption of benzene on the Fe (110) surface with a single Pd impurity at the first (left) and second (right) positions. The $E_{\mathrm{F}}$ has been set to zero, and the calculations were performed using the optB88 functional.

this interaction is still considerably weaker than the interactions between the remaining ring carbons and the Fe surface atoms.

The exact bonding nature between the ring carbons and bonding $\mathrm{Pd}$ or Fe atoms were investigated with the LDOS for each species of interest. This was done for the first and second positions. These positions were chosen because they had the highest interaction between the Pd impurity and adsorbate, and the resulting plots are shown in Figure 14.

From the adsorption configurations for each position, it is clear that there are several configurations of the aromatic ring carbons with respect to the surface Pd. For example, the first Pd position has three possible configurations $\left(\mathrm{C}_{2}, \mathrm{C}_{2^{\prime}}\right.$, and $\left.\mathrm{C}_{2^{\prime \prime}}\right)$ of the ring carbons with respect to the bonding surface $\mathrm{Pd}$ and $\mathrm{Fe}$ atoms while the second $\mathrm{Pd}$ position has four possible carbon configurations $\left(\mathrm{C}_{1}, \mathrm{C}_{1^{\prime}}, \mathrm{C}_{2}\right.$, and $\left.\mathrm{C}_{2^{\prime}}\right)$. The LDOS for all configurations were examined and showed almost no difference between the LDOS of the bonded carbon atom and the bonded surface atom, be it Fe or Pd. Therefore, the LDOS shown in Figure 14 are for the carbon-bonded Pd atom along with the carbon-bonded $\mathrm{Fe}$ atom opposite of the Pd atom along with the associated Pd-bonded ring carbon $\left(\mathrm{C}_{2^{\prime \prime}}\right.$ for the first position and $\mathrm{C}_{1}$ for the second). Here, we show both the spin up and spin down states for the bonded transition metal atoms along with the spin up states for the ring carbon. The spin down states for the ring carbon was also examined, and the difference in the LDOS between the two cases was found to be negligible.

The first obvious change is in the Pd LDOS which shows that the electronic structure has been significantly modified by its interaction with the Fe surface with a decrease in the spin up and down states near the Fermi level and the appearance of a large peak at $-3.5 \mathrm{eV}$ in the spin down states. These changes are evident by comparing the LDOS for the Pd in this surface with the previous PdFe surfaces and with a pure Pd (111) surface $^{29}$ along with the calculated d-band parameters. For the clean PdFe surface, the Pd's d-band center was found to shift by $\sim 1.1 \mathrm{eV}$ below the Fermi level relative to the Pd (111) surface while the d-bandwidth was found to increase by $\sim 5.9 \mathrm{eV}^{2}$. These changes show that the greater the amount of $\mathrm{Fe}$ in contact with the surface $\mathrm{Pd}$, the larger the hybridization of the Pd's 4d-band leading to weaker electronic interactions with the benzene adsorbate. Indeed, the adsorption of benzene on the surface Pd in this PdFe surface produces a minimal effect on Pd's states just below the Fermi level, reducing the strength of the surface's backdonation into the adsorbate's antibonding states. However, the appearance of a peak in the Pd's spin down LDOS at $\sim-4.5 \mathrm{eV}$ shows that this surface atom readily accepts electrons from benzene's HOMO level, suggesting that the decrease in benzene's adsorption strength due to interaction with the surface $\mathrm{Pd}$ is caused by a weakening in the backdonation of electrons from the surface.

Besides this change in the overall structure of the Pd LDOS, the adsorption of benzene on this surface produces results which are similar to the pure Fe (110) surface in the LDOS of the bonded carbon and Fe atoms. In the carbon's LDOS, the HOMO and LUMO levels have nearly disappeared upon adsorption due to similar electron transfer as seen in the pure Fe (110) surface. For the adjacent bonding surface Fe, peaks appear in the LDOS of the bonded $\mathrm{Fe}$ in the energy range from -8.0 to $-6.0 \mathrm{eV}$ which are caused by the overlap of the surface atom's orbitals with the higher energy orbitals of the adsorbate while the decrease in the Fe's available states below the Fermi level show that backdonation is occurring from this surface metal. These electronic interactions between the surface $\mathrm{Fe}$ and benzene's HOMO and LUMO levels were visualized, and the resulting partial charge densities are shown in Figure S11 of the Supporting Information. Finally, the change in the calculated dband center and width for the surface Fe adjacent to the Pd impurity is negligible, suggesting that the Fe's electronic structure remains relatively unchanged due to the overlap with the Pd's $4 \mathrm{~d}$ band and that benzene will strongly adsorb to the Fe surface away from surface Pd.

Overall, the results from these electronic comparisons support the conclusion formed from the trend in the adsorption energy, that the adsorption of benzene on an Fe (110) surface with a Pd impurity favors the $\mathrm{Fe}$ surface due to the rehybridization of the Pd's $4 \mathrm{~d}$ band.

\section{CONCLUSION}

The adsorption of benzene on a pure Fe (110) surface and several model PdFe surfaces was investigated using density functional theory. The examination of benzene adsorption on 
the pure $\mathrm{Fe}$ (110) surface resulted in an adsorption strength similar to that found on noble metals, such as Pt and Pd. ${ }^{32}$ Such a high adsorption energy was attributed to the strong electron donation and backdonation between surface and adsorbate as shown in the LDOS and charge densities.

The PdFe surfaces examined were a Pd (111) host with the first subsurface layer replaced with $\mathrm{Fe}$, a $\mathrm{Fe}(110)$ host with the first layer replaced with $\mathrm{Pd}$, and an Fe (110) host with a single, surface Pd impurity where the first two surfaces represent the high Pd coverage limit and the third surface represents the low Pd coverage limit. The resulting adsorption energies, molecular distortions, LDOS, and charge densities showed that the benzene adsorbate interacts more strongly with any exposed surface $\mathrm{Fe}$, despite the similar adsorption strength of benzene on the pure Pd and Fe surfaces. This is likely due to the shift in the Pd's d-band center away from the Fermi level which was found to be caused by a hybridization of Pd's 4d-band with the adjacent Fe's valence states. While the electronic structure of $\mathrm{Pd}$ in the PdFe surfaces was shown to drastically change relative to the $\mathrm{Pd}$ (111) surface, the Fe electronic structure remains largely unaffected by the $\mathrm{Pd}-\mathrm{Fe}$ interactions. Overall, these results show that benzene will preferentially adsorb onto any exposed $\mathrm{Fe}$ in a PdFe surface.

Our results show that the adsorption strength of benzene on PdFe surfaces can be tailored by varying the composition of $\mathrm{Pd}$ atop $\mathrm{Fe}$ surfaces through the variation of two parameters; the $\mathrm{Pd}: \mathrm{Fe}$ ratio and benzene surface coverage. First, variation in the surface Pd composition will alter the degree to which the Pd and benzene adsorbate interact and allow us to tune the adsorption strength of benzene. Second, increasing the benzene coverage to that expected under typical catalytic conditions will also increase the degree to which the surface Pd and adsorbate interact, decreasing the adsorption energy and allowing the average adsorption strength of benzene to be tuned. Therefore, the adsorption of benzene on PdFe surfaces can be effectively tailored by varying the surface Pd concentration.

\section{ASSOCIATED CONTENT}

\section{S Supporting Information}

Text describing additional surface segregation studies performed on $\mathrm{Pd}$ and $\mathrm{Fe}$ alloys along with an additional charge density analysis for the adsorption of benzene on the surfaces studied in this work as well as accompanying references, figures showing induced surface buckling due to benzene adsorption, the $\mathrm{Pd} / \mathrm{Fe}$ (110) model surfaces used for energetic feasibility testing for formation of the buckeled $\mathrm{Pd}$ adatom row, $\mathrm{Pd}_{3} \mathrm{Fe}$ (111) and PdFe (111) surfaces used for determining the nearsurface segregation trend, benzene-induced surface segregation of $\mathrm{Fe}$ in the $\mathrm{Pd} / \mathrm{Fe} / \mathrm{Pd}$ (111) surfaces, adsorption and segregation energies for benzene on $\mathrm{Pd} / \mathrm{Fe} / \mathrm{Pd}$ (111) surfaces, adsorbed carbon's p-orbital LDOS on the Fe (110) surface, orbital charge densities of the bonded carbon atom on the $\mathrm{Fe}$ (110) surface, and HOMO and LUMO charge densities for various ranges, and tables listing energies of formation for various supercells and for the $\mathrm{Pd} / \mathrm{Fe}$ (110) surface with and without the buckled adatom row and segregation energies for the $\mathrm{Pd}_{3} \mathrm{Fe}(111)$ and $\mathrm{PdFe}$ (111) surfaces. This material is available free of charge via the Internet at http://pubs.acs.org.

\section{AUTHOR INFORMATION}

\section{Corresponding Author}

*Tel.: 509-335-8580. Fax: 509-335-4806. E-mail: js.mcewen@ wsu.edu.

\section{Notes}

The authors declare no competing financial interest.

\section{ACKNOWLEDGMENTS}

This work was supported by institutional funds provided to J.S.M. from the Voiland School of Chemical Engineering and Bioengineering. J.S.M. thanks Prof. H.-P. Steinrück for his useful comments on the manuscript.

\section{REFERENCES}

(1) Adams, R. D.; Captain, B. Bimetallic Cluster Complexes: Synthesis, Structures and Applications to Catalysis. J. Organomet. Chem. 2004, 689 (24), 4521-4529.

(2) Sinfelt, J. H. Bifunctional Catalysis. Adv. Chem. Eng. 1964, 5, 3774.

(3) Sinfelt, J. H. Bimetallic Catalysts. Discoveries, Concepts and Applications; John Wiley and Sons: New York, NY, USA, 1983.

(4) Sinfelt, J. H. Bimetallic Catalysts. Sci. Am. 1985, 253 (3), 90-98.

(5) Sinfelt, J. H. Catalysis by Alloys and Bimetallic Clusters. Acc. Chem. Res. 1977, 10, 15-20.

(6) Sachtler, W. M. H. Selectivity and Rate of Activity Decline of Bimetallic Catalysts. J. Mol. Catal. 1984, 25 (1-3), 1-12.

(7) Sachtler, W. M. H.; Van Santen, R. A. Surface Composition and Selectivity of Alloy Catalysts. Adv. Catal. 1977, 26, 69-119.

(8) Guzci, L. Mechanism of Reactions on Multimetallic Catalysts. J. Mol. Catal. 1984, 25 (1-3), 13-29.

(9) Oh, S. H.; Carpenter, J. E. Platinum-Rhodium Synergism in Three-Way Automative Catalysts. J. Catal. 1986, 98 (1), 178-190.

(10) Wang, T.; Schmidt, L. D. Surface Enrichment of Pt-Rh Alloy Particles by Oxidation-Reduction Cycling. J. Catal. 1981, 71 (2), 411422.

(11) Barbier, J., Jr.; Duprez, D. Steam Effects in Three-Way Catalysis. Appl. Catal., B 1994, 4 (2-3), 105-140.

(12) Lo, J. M. H.; Ziegler, T. Computational Studies of the Adsorption and Diffusion of Hydrogen on $\mathrm{Fe}-\mathrm{Co}$ Alloy Surfaces. J. Phys. Chem. C 2008, 112, 3667-3678.

(13) Amelse, J. A.; Schwartez, L. H.; Butt, J. B. Iron Alloy FischerTropsch Catalysts: III. Conversion Dependence of Selectivity and Water-Gas Shift. J. Catal. 1981, 72 (1), 95-110.

(14) Arcuri, K. B.; Schwartz, L. H.; Piotrowski, R. D.; Butt, J. B. Iron Alloy Fischer-Tropsch Catalysts: IV. Reaction and Selectivity Studies of the FeCo System. J. Catal. 1984, 85 (2), 349-361.

(15) Lin, T.; Schwartz, L. H.; Butt, J. B. Iron Alloy Fischer-Tropsch Catalysts: V. FeCo on Y Zeolite. J. Catal. 1986, 97 (1), 177-187.

(16) Butt, J. B.; Lin, T. A.; Schwartz, L. H. Iron Alloy FischerTropsch Catalysts: VI. FeCo on ZSM-5. J. Catal. 1986, 97 (1), 261263.

(17) Desai, S.; Neurock, M. A First Principles Analysis of CO Oxidation over $\mathrm{Pt}$ and $\mathrm{Pt}_{66.7 \%} \mathrm{Ru}_{33.3 \%}$ (111) Surfaces. Electrochim. Acta 2003, 48 (25-26), 3759-3773.

(18) Hogarth, M. P.; Hards, G. A. Direct Methanol Fuel Cells: Technological Advances and Further Requirements. Platinum Met. Rev. 1996, 40 (4), 150-159.

(19) Rolison, D. R.; GHagans, P. L.; Swider, K. E.; Long, J. W. Role of Hydrous Ruthenium Oxide in Pt-Ru Direct Methanol Fuel Cell Anode Electrocatalysts: The Importance of Mixed Electron/Proton Conductivity. Langmuir 1999, 15, 774-779.

(20) Steigerwalt, E. S.; Deluga, G. A.; Cliffel, D. E.; Lukehart, C. M. A $\mathrm{Pt}-\mathrm{Ru} / \mathrm{Graphite}$ Carbon Nanofiber Nanocomposite Exhibiting High Relative Performance as a Direct Methanol Fuel Cell Anode Catalyst. J. Phys. Chem. B 2001, 105, 8097-8101.

(21) Sun, J.; Karim, A. M.; Zhang, H.; Kovarik, L.; Li, X.; Hensley, A. J.; McEwen, J.-S.; Wang, Y. Carbon Supported Bimetallic Pd-Fe Catalysts for Vapor-Phase Hydrodeoxygenation of Guaiacol. J. Catal. 2013, 306, 47-57.

(22) Nashner, M. S.; Frenkel, A. I.; Somerville, D.; Hills, C. W.; Shapley, J. R.; Nuzzo, R. G. Core Shell Inversion during Nucleation 
and Growth of Bimetallic Pt/Ru Nanoparticles. J. Am. Chem. Soc. 1998, 120, 8093-8101.

(23) Nashner, M. S.; Frenkel, A. I.; Adler, D. L.; Shapley, J. R.; Nuzzo, R. G. Structural Characterization of Carbon-Supported Platinum-Ruthenium Nanoparticles from the Molecular Cluster Precursor $\mathrm{PtRu}_{5} \mathrm{C}(\mathrm{Co})_{16}$. J. Am. Chem. Soc. 1997, 119, 7760-7771.

(24) Hills, C. W.; Nashner, M. S.; Frenkel, A. I.; Shapley, J. R.; Nuzzo, R. G. Carbon Support Effects on Bimetallic Pt-Ru Nanoparticles Formed from Molecular Precusors. Langmuir 1999, $15,690-700$.

(25) Sinfelt, J. H. Structure of Bimetallic Clusters. Acc. Chem. Res. 1987, 20, 134-139.

(26) Meitzner, G.; Via, G. H.; Lytle, F. W.; Sinfelt, J. H. Structure of Bimetallic Clusters. Extended X-ray Adsorption Fine Structure (EXAFS) of Pt-Re and Pd-Re Clusters. J. Chem. Phys. 1987, 87 (11), 6354-6363.

(27) Tereshchuk, P.; Da Silva, J. L. F. Ethanol and Water Adsorption on Close-Packed 3d, 4d, and 5d Transition-Metal Surfaces: A Density Functional Theory Investigation with van der Waals Correction. J. Phys. Chem. C 2012, 116, 24695-24705.

(28) Saeys, M.; Reyniers, M.-F.; Marin, G. B.; Neurock, M. Density Functional Study of Benzene Adsorption on Pt(111). J. Phys. Chem. B 2002, 106, 7489-7498.

(29) Morin, C.; Simon, D.; Sautet, P. Intermediates in the Hydrogenation of Benzene to Cyclohexene on $\mathrm{Pt}(111)$ and $\operatorname{Pd}(111)$ : A Comparison from DFT Calculations. Surf. Sci. 2006, 600 (6), 1339-1350.

(30) Morin, C.; Simon, D.; Sautet, P. Chemisorption of Benzene on $\operatorname{Pt}(111), \operatorname{Pd}(111)$, and $\mathrm{Rh}(111)$ Metal Surfaces: A Structural and Vibrational Comparison from First Principles. J. Phys. Chem. B 2004, 108, 5653-5665.

(31) Orita, H.; Itoh, N. Simulation of Phenol Formation from Benzene with a Pd Membrane Reactor: Ab Initio Periodic Density Functional Study. Appl. Catal., A 2004, 258 (1), 17-23.

(32) Liu, W.; Carrasco, J.; Santra, B.; Michaelides, A.; Scheffler, M.; Tkatchenko, A. Benzene Adsorbed on Metals: Concerted Effect of Covalency and van der Waals Bonding. Phys. Rev. B: Condens. Matter Mater. Phys. 2012, 86 (24), No. 245405.

(33) Liu, W.; Ruiz, V. G.; Zhang, G.-X.; Santra, B.; Ren, X.; Scheffler, M.; Tkatchenko, A. Structure and Energetics of Benzene Adsorbed on Transition-Metal Surfaces: Density-Functional Theory with van der Waals Interactions Including Collective Substrate Response. New J. Phys. 2013, 15 (5), 053046.

(34) Sun, X.; Suzuki, T.; Kurahashi, M.; Zhang, J. W.; Yamauchi, Y. First-Principles Study on the Spin Polarization of Benzene Adsorbed on $\mathrm{Fe}(100)$ Surface. J. Appl. Phys. 2007, 101 (9), No. 09G526.

(35) Sun, X.; Yamauchi, Y.; Kurahashi, M.; Suzuki, T.; Wang, Z. P.; Entani, S. Spin Polarization Study of Benzene Molecule Adsorbed on $\mathrm{Fe}(100)$ Surface with Metastable-Atom Deexcitation Spectroscopy and Density Functional Calculations. J. Phys. Chem. C 2007, 111, 1528915298 .

(36) Kresse, G.; Furthmueller, J. Efficient Iterative Schemes for $A b$ Initio Total-Energy Calculations using a Plane-Wave Basis Set. Phys. Rev. B: Condens. Matter Mater. Phys. 1996, 54 (16), 11169-11186.

(37) Kresse, G.; Hafner, J. Ab Initio Molecular Dynamics for Liquid Metals. Phys. Rev. B: Condens. Matter Mater. Phys. 1993, 47 (1), 558561.

(38) Kresse, G.; Joubert, D. From Ultrasoft Psuedopotentials to the Projector Augmented-Wave Method. Phys. Rev. B: Condens. Matter Mater. Phys. 1999, 59 (3), 1758-1775.

(39) Blöchl, P. E. Projector Augmented-Wave Method. Phys. Rev. B: Condens. Matter Mater. Phys. 1994, 50 (24), 17953-17979.

(40) Jenkins, S. J. Aromatic Adsorption on Metals via First-Principles Density Functional Theory. Proc. R. Soc. A 2009, 465 (2110), 29492976.

(41) Klimeš, J.; Bowler, D. R.; Michaelides, A. Van der Waals Density Functionals Applied to Solids. Phys. Rev. B: Condens. Matter Mater. Phys. 2011, 83 (19), No. 195131.
(42) Hammer, B.; Hansen, L. B.; Nørskov, J. K. Improved Adsorption Energetics within Density-Functional Theory using Revised Perdew-Burke-Ernzerhof Functionals. Phys. Rev. B: Condens. Matter Mater. Phys. 1999, 59 (11), 7413-7421.

(43) Perdew, J. P.; Burke, K.; Ernzerhof, M. Generalized Gradient Approximation Made Simple. Phys. Rev. Lett. 1996, 77 (18), 38653868.

(44) Monkhorst, H. J.; Pack, J. D. Special Points for Brillouin-Zone Integrations. Phys. Rev. B: Condens. Matter Mater. Phys. 1976, 13 (12), $5188-5192$.

(45) Methfessel, M.; Paxton, A. T. High-Precision Sampling for Brillouin-Zone Integration in Metals. Phys. Rev. B: Condens. Matter Mater. Phys. 1989, 40 (6), 3616-3621.

(46) Błoński, P.; Lehnert, A.; Dennler, S.; Rusponi, S.; Etzkorn, M.; Moulas, G.; Bencok, P.; Gambardella, P.; Brune, H.; Hafner, J. Magnetocrystalline Anisotropy Energy of $\mathrm{Co}$ and $\mathrm{Fe}$ Adatoms on the (111) Surfaces of Pd and Rh. Phys. Rev. B: Condens. Matter Mater. Phys. 2010, 81 (10), No. 104426.

(47) Barreteau, C.; Guirado-López, R.; Spanjaard, D.; Desjonquéres, M. C.; Olés, A. M. spd Tight-Binding Model of Magnetism in Transition Metals: Application to Rh and Pd Clusters and Slabs. Phys. Rev. B: Condens. Matter Mater. Phys. 2000, 61 (11), 7781-7794.

(48) Makov, G.; Payne, M. C. Periodic Boundary Conditions in $A b$ Initio Calculations. Phys. Rev. B: Condens. Matter Mater. Phys. 1995, 51 (7), 4014-4022.

(49) Ruban, A. V.; Skriver, H. L.; Nørskov, J. K. Surface Segregation Energies in Transition-Metal Alloys. Phys. Rev. B: Condens. Matter Mater. Phys. 1999, 59 (24), 15990-16000.

(50) Nilekar, A. U.; Ruban, A. V.; Mavrikakis, M. Surface Segregation Energies in Low-Index Open Surfaces of Bimetallic Transition Metal Alloys. Surf. Sci. 2009, 603 (1), 91-96.

(51) Vitos, L.; Ruban, A. V.; Skriver, H. L.; Kollar, J. The Surface Energy of Metals. Surf. Sci. 1998, 411 (1-2), 186-202.

(52) Zhong, W.; Overney, G.; Tomanek, D. Structural Properties of Fe Crystals. Phys. Rev. B: Condens. Matter Mater. Phys. 1993, 47 (1), 95-99.

(53) Makkonen, I.; Salo, P.; Alatalo, M.; Rahman, T. S. Ab Initio Studies of Stepped Pd Surfaces with and without S. Phys. Rev. B: Condens. Matter Mater. Phys. 2003, 67 (16), No. 165415.

(54) Herron, J. A.; Tonelli, S.; Mavrikakis, M. Atomic and Molecular Adsorption on Pd(111). Surf. Sci. 2012, 606 (21-22), 1670-1679.

(55) Mohri, T.; Chen, Y. First-Principles Investigation of L10Disorder Phase Equilibria of $\mathrm{Fe}-\mathrm{Ni},-\mathrm{Pd}$, and $-\mathrm{Pt}$ Binary Alloy Systems. J. Alloys Compd. 2004, 383 (1-2), 23-31.

(56) Santarossa, G.; Iannuzzi, M.; Vargas, A.; Baiker, A. Adsorption of Naphthalene and Quinoline on $\mathrm{Pt}, \mathrm{Pd}$ and $\mathrm{Rh}$ : A DFT Study. ChemPhysChem 2008, 9 (3), 401-413.

(57) Mittendorfer, F.; Hafner, J. Density-Functional Study of the Adsorption of Benzene on the (111), (100), and (110) Surfaces of Nickel. Surf. Sci. 2001, 472 (1-2), 133-153.

(58) Hammer, B.; Nørskov, J. K. Electronic Factors Determining the Reactivity of Metal Surfaces. Surf. Sci. 1995, 343 (3), 211-220.

(59) Nфrskov, J. K.; Abild-Pedersen, F.; Studt, F.; Bligaard, T. Density Functional Theory in Surface Chemistry and Catalysis. Proc. Natl. Acad. Sci. U. S. A. 2011, 108 (3), 937-943.

(60) Hammer, B.; Nørskov, J. K. Theoretical Surface Science and Catalysis - Calculations and Concepts. Adv. Catal. 2000, 45, 71-129.

(61) Kitchin, J. R.; Nфrskov, J. K.; Barteau, M. A.; Chen, J. G. Modification of the Surface Electronic and Chemical Properties of Pt(111) by Subsurface 3d Transition Metals. J. Chem. Phys. 2004, 120 (21), 10240-10246.

(62) Schweitzer, N.; Xin, H.; Nikolla, E.; Miller, J. T.; Linic, S. Establishing Relationships Between the Geometric Structure and Chemical Reactivity of Alloy Catalysts Based on Their Measured Electronic Structure. Top. Catal. 2010, 53 (5-6), 348-356. 